\title{
Transport of LDL-derived cholesterol from the NPC1 compartment to the ER involves the trans-Golgi network and the SNARE protein complex
}

\author{
Yasuomi Urano a, Hiroshi Watanabe ${ }^{a}$, Stephanie R. Murphya ${ }^{a}$, Yohei Shibuyaa, Yong Genga ${ }^{a}$ Andrew A. Peden ${ }^{b, 1}$, \\ Catherine C. Y. Chang ${ }^{\mathrm{a}}$, and Ta Yuan Chang ${ }^{\mathrm{a}, 2}$ \\ ${ }^{a}$ Department of Biochemistry, Dartmouth Medical School, Hanover, NH 03755; and bGenentech, Inc., South San Francisco, CA 94080
}

Edited by David W. Russell, University of Texas Southwestern Medical Center, Dallas, TX, and approved September 18, 2008 (received for review July 31,2008$)$

\begin{abstract}
Mammalian cells acquire cholesterol mainly from LDL. LDL enter the endosomes, allowing cholesteryl esters to be hydrolyzed by acid lipase. The hydrolyzed cholesterol (LDL-CHOL) enters the NiemannPick type C1 (NPC1)-containing endosomal compartment en route to various destinations. Whether the Golgi is involved in LDL-CHOL transport downstream of the NPC1 compartment has not been demonstrated. Using subcellular fractionation and immunoadsorption to enrich for specific membrane fractions, here we show that, when parental Chinese hamster ovary $(\mathrm{CHO})$ cells are briefly exposed to ${ }^{3} \mathrm{H}$-cholesteryl linoleate (CL) labeled-LDL, newly liberated ${ }^{3} \mathrm{H}-\mathrm{LDL}$ CHOL appears in membranes rich in trans-Golgi network (TGN) long before it becomes available for re-esterification at the endoplasmic reticulum (ER) or for efflux at the plasma membrane. In mutant cells lacking NPC1, the appearance of newly liberated ${ }^{3} \mathrm{H}-\mathrm{LDL}-\mathrm{CHOL}$ in the TGN-rich fractions is much reduced. We next report a reconstituted transport system that recapitulates the transport of LDL-CHOL to the TGN and to the ER. The transport system requires ATP and cytosolic factors and depends on functionality of NPC1. We demonstrate that knockdown by RNAi of 3 TGN-specific SNAREs (VAMP4, syntaxin 6, and syntaxin 16 ) reduces $\geq 50 \%$ of the LDL-CHOL transport in intact cells and in vitro. These results show that vesicular trafficking is involved in transporting a significant portion of LDL-CHOL from the NPC1-containing endosomal compartment to the TGN before its arrival at the ER.
\end{abstract}

lipid metabolism | membrane trafficking | vesicular transport

V arious bodily cells receive cholesterol mainly via LDL, the major cholesterol carrier in the blood cholesteryl ester (CE). In human LDL, cholesteryl linoleate (CL) is the predominant CE. LDL enters the cells mainly via LDL receptor mediated endocytosis (1). The endocytosed CE undergoes hydrolysis in an early endosomal compartment enriched in acid lipase (2); the cholesterol released then emerges in endosomes containing the protein $\mathrm{Ni}$ emann-Pick type C1 (NPC1); from the NPC1 compartment(s), the LDL-derived cholesterol (LDL-CHOL) moves to various destinations including the plasma membrane (PM) and the endoplasmic reticulum (ER), etc. (2-4). At the ER, the LDL-CHOL can be re-esterified to $\mathrm{CE}$ by acyl-CoA:cholesterol acyltransferase (ACAT). There are 2 ACAT isoenzymes, ACAT1 and ACAT2. In healthy humans, ACAT1 is the main isoenzyme in most cell types, whereas ACAT2 is the main isoenzyme in intestinal enterocytes (5).

The NPC1 and NPC2 proteins play important roles in LDLCHOL transport. NPC1 is a multispan membrane protein localized to a unique set of endosomes $(6,7)$; the NPC1-GFP fusion protein is also present in vesicles budding off from the endosomes (8). NPC2 is a soluble glycoprotein in the lumen of the late endosomes/ lysosomes (LE/LYS) (9). Both NPC1 and NPC2 bind to cholesterol (10-15) and may cooperate in endosomal cholesterol transport (16). Whether the Golgi is involved in LDL-CHOL transport downstream of the NPC1 compartment has not yet been demonstrated. To address these issues, we performed pulse-chase experiments in $\mathrm{CHO}$ cells with LDL that contained ${ }^{3} \mathrm{H}$-cholesteryl linoleate $\left({ }^{3} \mathrm{H}-\mathrm{CL}-\mathrm{LDL}\right)$ to monitor the fate of ${ }^{3} \mathrm{H}-\mathrm{LDL}-\mathrm{CHOL}$ liberated in a time-dependent manner. We also developed an in vitro system that efficiently recapitulates the NPC1-dependent re-esterification of ${ }^{3} \mathrm{H}-\mathrm{LDL}-\mathrm{CHOL}$ and used this system to study the mechanism of LDL-CHOL transport.

\section{Results}

Nocodazole or Brefeldin A (BFA) Affects the Re-Esterification and Efflux of ${ }^{3} \mathrm{H}$-LDL-CHOL. For most of the studies reported here, we used a parental CHO cell line, 25RA (17) and a mutant NPC1 cell line, CT43 cells. 25RA cells contain a mutation in the sterol regulatory element-binding protein (SREBP) cleavage-activating protein (SCAP), which constitutively activates SREBP processing in a sterol-independent manner (18). CT43 cells are NPC1-null cells derived from 25RA cells (19). Findings made in this cell system are generally applicable to other cell types $(8,20-22)$. To monitor the hydrolysis and transport of ${ }^{3} \mathrm{H}-\mathrm{LDL}-\mathrm{CHOL}$ liberated from ${ }^{3} \mathrm{H}-\mathrm{CL}$, we pulse-labeled cells with ${ }^{3} \mathrm{H}$-CL-LDL for $30 \mathrm{~min}$, then chased the cells without ${ }^{3} \mathrm{H}$-CL-LDL for up to $6 \mathrm{~h}$ [supporting information (SI) Fig. S1A]. The percentage of ${ }^{3} \mathrm{H}-\mathrm{LDL}-\mathrm{CHOL}$ re-esterified by ACAT1 was used to estimate ${ }^{3} \mathrm{H}-\mathrm{LDL}-\mathrm{CHOL}$ arrival at the ER. We also used the availability of labeled sterol to cyclodextrin (CD) in medium for $10 \mathrm{~min}$ to examine the movement of ${ }^{3} \mathrm{H}-\mathrm{LDL}-\mathrm{CHOL}$ to the PM (2). The results indicate that in the 25RA cells, the re-esterification of ${ }^{3} \mathrm{H}-\mathrm{LDL}-\mathrm{CHOL}$ occurs and increases linearly with time for up to $6 \mathrm{~h}$, whereas in CT43 cells, re-esterification remains uniformly deficient (Fig. $\mathrm{S} 1 B$ ). As the chase time increases from $20 \mathrm{~min}$ to $2 \mathrm{~h}$, both the percentage re-esterification and the CD-mediated efflux of ${ }^{3} \mathrm{H}$-LDL-CHOL increased significantly in 25RA cells but not in CT43 cells (Fig. S1C Middle and Bottom) (2). The percentage hydrolysis of ${ }^{3} \mathrm{H}-\mathrm{CL}$ in CT43 cells was similar to that of 25RA cells (Fig. S1C Top). These results confirm previous studies $(2,3)$ and indicate that in cells lacking functional NPC1, the movement of LDL-CHOL from the NPC1 compartment to the ER and to the PM is defective. Using the pulse-chase protocol, we tested the effects of several compounds (cytochalasin D, wortmannin, latrunculin A, nocodazole, BFA, etc.) in 25RA cells for their ability to interfere with re-esterification or with efflux of ${ }^{3} \mathrm{H}-\mathrm{LDL}$ CHOL. Because these compounds can also affect the endocytosis/ internalization of the LDL (23), we treated cells with the test

Author contributions: Y.U. and T.Y.C. designed research; Y.U., H.W., S.R.M., and Y.S performed research; Y.G. and A.A.P. contributed new reagents/analytic tools; Y.U., H.W., Y.S., and C.C.Y.C. analyzed data; and Y.U. and T.Y.C. wrote the paper.

The authors declare no conflict of interest.

This article is a PNAS Direct Submission.

1Present address: Cambridge Institute for Medical Research, Addenbrooke's Hospital, Cambridge CB2, U.K.

2To whom correspondence should be addressed. E-mail: ta.yuan.chang@dartmouth.edu. This article contains supporting information online at www.pnas.org/cgi/content/full/ 0807450105/DCSupplemental.

() 2008 by The National Academy of Sciences of the USA 
compound only during the chase but not during the pulse. The results (Fig. S1D) showed that nocodazole, an agent that disrupts the microtubules and disintegrates the Golgi within minutes (24), inhibited the re-esterification and efflux of ${ }^{3} \mathrm{H}-\mathrm{LDL}-\mathrm{CHOL}$ by $\approx 50 \%$ (Fig. S1D Middle and Bottom). BFA, which causes fusion of the Golgi with the ER (25), inhibited efflux to the PM by $\approx 40 \%$ and increased re-esterification of ${ }^{3} \mathrm{H}-\mathrm{LDL}-\mathrm{CHOL}$ by $\approx 20 \%$. These results suggest the involvement of the Golgi in the transport of LDL-CHOL and are consistent with a previous result using BFA in human fibroblast cells (26). Other drugs tested did not show significant effects on re-esterification (data not shown).

Fate of ${ }^{3} \mathrm{H}-\mathrm{LDL}-\mathrm{CHOL}$ Downstream of the NPC1 Compartment. It is possible that the effects of nocodazole or BFA on re-esterification and on efflux of ${ }^{3} \mathrm{H}$-LDL-CHOL described above may be unrelated to their ability to disrupt the Golgi function. To further test the possibility that ${ }^{3} \mathrm{H}-\mathrm{LDL}-\mathrm{CHOL}$ may move from the NPC1containing compartment to the Golgi, we monitored the fate of ${ }^{3}$ H-LDL-CHOL by performing subcellular fractionation of labeled cell extracts. We first showed that the cellular organelles are separated into 6 major fractions (Figs. $1 A$ and S2). NPC1 and NPC2 are principally located in fraction 6 (Fig. S2) but not in fraction 2 , where LE/LYS are located. The same NPC1/NPC2 distribution patterns occurred in 25RA and WT CHO cell extracts (data not shown). These results suggest that in CHO cells, NPC1, and NPC2 are located in fractions distinct from the LE/LYS. In our current work, we designate the endocytic compartment(s) that contain NPC1 as "the NPC1 compartment."

We next performed pulse-chase experiments and tracked the labeled cholesterol in various subcellular organelles. The results (Fig. $1 B$ Left) show that at 0 time, in both the 25RA (blue) and the CT43 cell extracts (red), ${ }^{3} \mathrm{H}-\mathrm{LDL}-\mathrm{CHOL}$ was enriched in fractions 4 and 5. At 20-min chase, in 25RA cells, fraction 5, rich in the Golgi and the early endosome (EE), was enriched in ${ }^{3} \mathrm{H}-\mathrm{LDL}-\mathrm{CHOL}$. In the CT43 cells, ${ }^{3} \mathrm{H}-\mathrm{LDL}-\mathrm{CHOL}$ was enriched in fraction 2 , rich in LE/LYS, consistent with the previous finding that in mutant NPC1 cells, cellular cholesterol accumulates abnormally within the LE/ LYS (27). At later time point $(2 \mathrm{~h})$, in $25 \mathrm{RA}$ cell extracts, the ${ }^{3}$ H-LDL-CHOL appeared in fractions with higher densities (i.e., PM, ER, and mitochondria), whereas in CT43 cell extracts, the ${ }^{3} \mathrm{H}$-LDL-CHOL remained in fraction 2 . The distributions of ${ }^{3} \mathrm{H}-\mathrm{CL}$ are very similar in 25RA and CT43 cells (Fig. $1 B$ Right). For ${ }^{3} \mathrm{H}-\mathrm{CO}$, it appeared as lipid droplets (fractions 1) in 25RA cells after $2 \mathrm{~h}$, whereas no ${ }^{3} \mathrm{H}-\mathrm{CO}$ was produced in CT43 cells (data not shown). The drug U-18666A causes treated cells to exhibit a phenotype similar to that of NPC mutants (28). We performed additional experiments and found that the distribution patterns of ${ }^{3} \mathrm{H}-\mathrm{LDL}$ CHOL from 25RA cells treated with U-18666A for $24 \mathrm{~h}$ were essentially the same as those of the CT43 cells (Fig. S3A). Additional experiments show that when 25RA cells were pulsed with ${ }^{3} \mathrm{H}-\mathrm{CL}-\mathrm{LDL}$ and chased for $2 \mathrm{~h},{ }^{3} \mathrm{H}-\mathrm{LDL}-\mathrm{CHOL}$ accumulated in the lower-density endosomal fractions (fractions 2 and 4) in nocodazole-treated cells during the chase, suggesting that rapid Golgi disintegration and microtubule disruption may create a transient NPC1-null phenotype, causing a significant portion of the LDL$\mathrm{CHOL}$ to accumulate in the endosomes.

LDL-CHOL Moves from the NPC1 Compartment to the TGN. Subcellular fractionation can provide only partially purified membranes. To further explore the possibility that Golgi membranes may participate in LDL-CHOL transport, we used beads coated with antibodies against syntaxin 16, a TGN-protein marker, and performed selective immunoadsorption (IA) on post-nuclear supernatants (PNSs) prepared from 25RA cells. Beads coated with nonspecific rabbit antibodies were used as control. Immunoblot analysis revealed that the anti-syntaxin 16 adsorbed most of the syntaxin 16 and syntaxin 6-positive membranes (Fig. $2 A$ ); these membranes also contained a significant amount of the protein called vesicle-
A

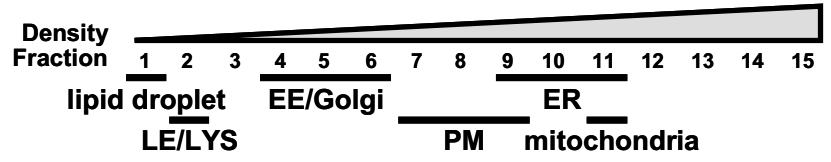

B
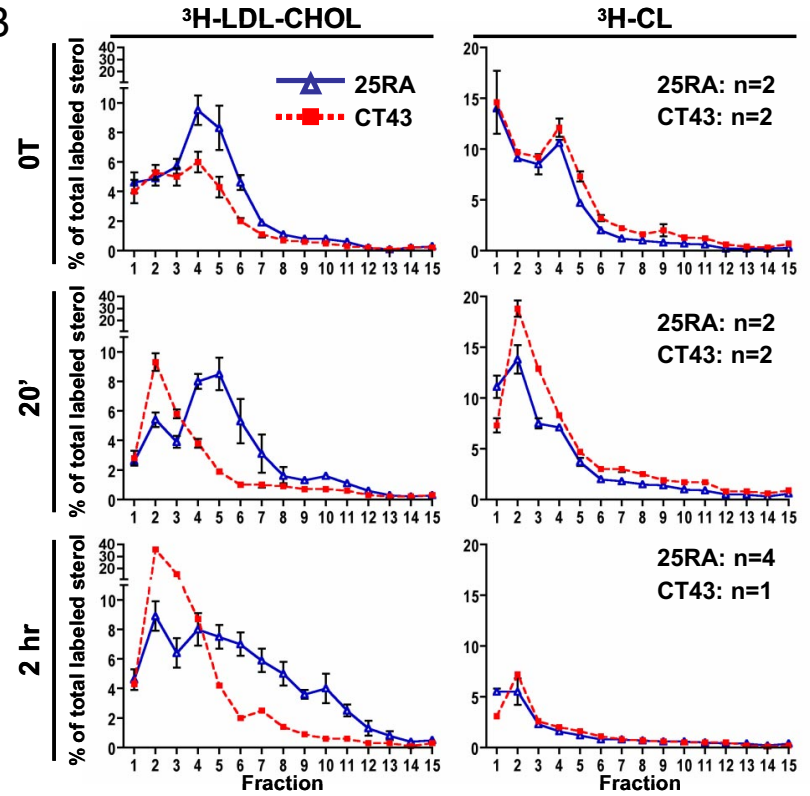

Fig. 1. ${ }^{3} \mathrm{H}-\mathrm{LDL}-\mathrm{CHOL}$ distribution after pulse and various chase periods. $(A)$ Organelle marker distribution patterns after subcellular fractionation by OptiPrep density gradient ultracentrifugation. (B) Cells were pulsed with ${ }^{3} \mathrm{H}-\mathrm{CL}-\mathrm{LDL}$ and chased for 0 time (OT) to $2 \mathrm{~h}$; PNSs were fractionated. At 20-min chase time, ${ }^{3} \mathrm{H}-\mathrm{LDL}-\mathrm{CHOL}$ appears in TGN-rich fraction from 25RA cells but not from CT43 cells. Equal aliquots from each fraction were analyzed for labeled lipids. $\mathrm{N}$ indicates the number of the experiments performed. The data are means \pm SD.

associated membrane protein 4 (VAMP4) and a small amount of caveolin-1 (cav1). These results are consistent with previous findings that syntaxin 6 , syntaxin 16 , and VAMP4 form the soluble $\mathrm{N}$-ethylmaleimide (NEM)-sensitive factor (NSF) attachment protein receptor (SNARE) complex at the TGN (29), and that cav1 and syntaxin 6 can form a tight complex in the TGN membranes (30). The syntaxin 16-positive membranes did not contain any detectable amount of the early endosomal marker EEA1. We next performed pulse-chase and monitored the presence of ${ }^{3} \mathrm{H}$-LDLCHOL in the syntaxin 16-rich membranes by IA. The results indicate (Fig. 2C) that in the 25RA cell extracts, ${ }^{3} \mathrm{H}-\mathrm{LDL}-\mathrm{CHOL}$ was associated with the syntaxin 16-rich membranes at 0 time; the association was increased after the 20 -min chase. In the CT43 cell extracts, however, such association was less at 0 time, and no increase in association was observed after the 20-min chase. To expand on this observation, we carried out similar IA experiments by using beads coated with anti-syntaxin 6 -specific antibodies or with nonspecific rabbit IgGs. We used a pool of OptiPrep fraction 5 membranes isolated from the 25RA cells as the starting materials. The immunoblot analysis revealed that anti-syntaxin 6 immunoadsorbed essentially all of the syntaxin 6-positive membranes; these membranes also contained a small amount of cav1 but did not contain EEA1 or NPC1 (Fig. $2 B$ ). We next performed a pulse followed by a 20 -min chase in both the 25RA cells and the CT43 cells, isolated OptiPrep fraction 5 from the cell extracts, and carried out the IAs from these fractions. The results show that in the 25RA cell extracts, a significant amount of ${ }^{3} \mathrm{H}-\mathrm{LDL}-\mathrm{CHOL}$ was associated with the syntaxin 6-rich membranes; whereas in the CT43 cell extracts, such association was much lower (Fig. 2D). Together, these 

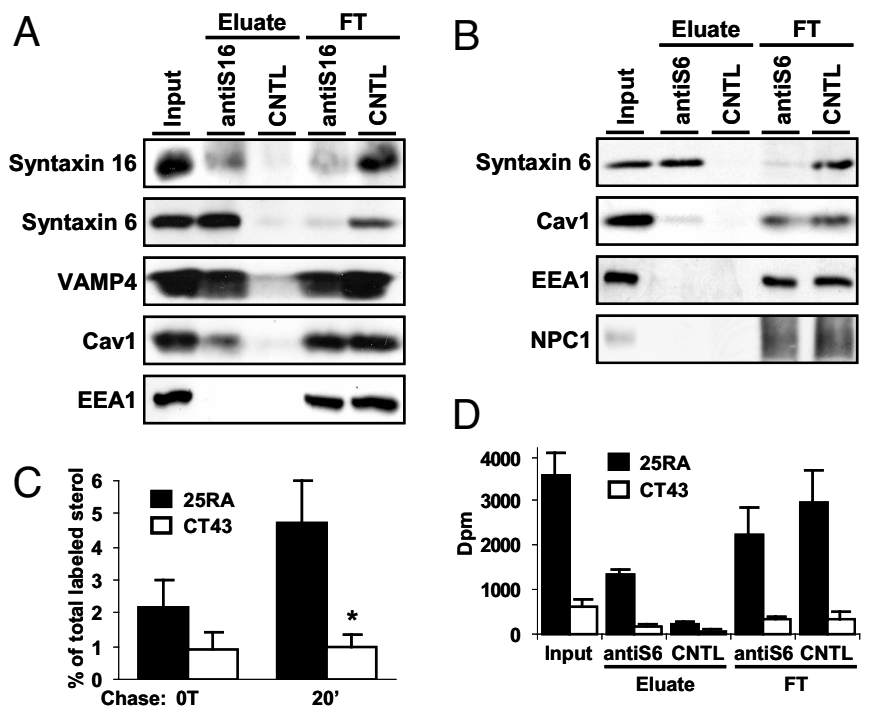

Fig. 2. Association of ${ }^{3} \mathrm{H}-\mathrm{LDL}-\mathrm{CHOL}$ with syntaxin 6-rich and syntaxin 16-rich membranes in intact 25RA cells. The 25RA and CT43 cells were pulsed with ${ }^{3} \mathrm{H}-\mathrm{CL}-\mathrm{LDL}$ and chased in Medium $\mathrm{A}$ for $20 \mathrm{~min}$. ( $A$ and $C$ ) The PNSs were immunoadsorbed with rabbit anti-syntaxin 16 (antiS16) antibodies or nonspecific rabbit antibodies (CNTL). ( $B$ and $D$ ) The PNSs were fractionated by OptiPrep density gradient ultracentrifugation; the syntaxin 6-rich fractions (fraction 5) were isolated and immunoadsorbed with rabbit anti-syntaxin 6 (antiS6) antibodies or nonspecific rabbit antibodies (CNTL). ( $A$ and $B$ ) Associated proteins were analyzed by immunoblot using appropriate antibodies as indicated. The 25RA cells were used. (C and D) ${ }^{3} \mathrm{H}$-LDL-CHOL counts in the eluates were analyzed after lipid extraction and TLC. Values are presented as the percentage of total labeled sterol $(C)$. The data are means \pm SD from 2 experiments. *, $P<0.05$ by Student's $t$ test.

results are evidence that a significant portion of the LDL-CHOL is present in syntaxin 6- and syntaxin 16-rich TGN membranes, and that the movement of LDL-CHOL to the TGN depends on functional NPC1.

Transport of LDL-CHOL from Endosomes to the ER in Vitro. We next used the re-esterification of ${ }^{3} \mathrm{H}-\mathrm{LDL}-\mathrm{CHOL}$ as a reporter for its arrival at the $\mathrm{ER}$, and developed an in vitro assay that recapitulates the NPC1-dependent transport of LDL-CHOL in intact cells. We found that cells permeabilized with $0.001-0.003 \%$ digitonin at $4{ }^{\circ} \mathrm{C}$ for 5-15 min constituted a robust and reproducible in vitro system for LDL-CHOL transport in 25RA cells (outlined in Fig. 3A). We loaded the ${ }^{3} \mathrm{H}$-CL-LDL in intact $25 \mathrm{RA}$ cells by performing a pulse, then prepared semi-intact cells by permeabilizing the cell monolayers. We then added various factors, including rat liver cytosol, ATP/GTP, and oleoyl-CoA (as a substrate by ACAT1 in vitro), individually or in combination, and monitored the re-esterification of ${ }^{3} \mathrm{H}$-LDL-CHOL with time. We also conducted parallel experiments in AC29 cells. AC29 cells are mutant cells derived from 25RA cells, but AC29 cells lack ACAT1 (31). As shown in Fig. $3 B$ Top, after incubation at $37^{\circ} \mathrm{C}$ for $3 \mathrm{~h}$, the hydrolysis of ${ }^{3} \mathrm{H}-\mathrm{CL}-\mathrm{LDL}$ significantly increased in both 25RA and AC29 cells; however, significant re-esterification of ${ }^{3} \mathrm{H}$-LDL-CHOL occurred in 25RA cells but not in AC29 cells (Fig. 3B Bottom), demonstrating the dependency of re-esterification on ACAT1. Omitting ATP/GTP or cytosolic factors from the incubation mixture severely diminished re-esterification activity; omitting oleoyl-CoA partially reduced the activity (Fig. 3B Bottom). A separate experiment demonstrated that adding GTP $\gamma \mathrm{S}$ (a nonhydrolyzable analog of GTP) also diminished the re-esterification activity in reconstituted 25RA cell system (data not shown). Additional experiments (Fig. 3C) show that after incubating at $37^{\circ} \mathrm{C}$ for $>1 \mathrm{~h},{ }^{3} \mathrm{H}$-LDL-CHOL re-esterification in reconstituted $25 \mathrm{RA}$ cell system increased with time for up to $3 \mathrm{~h}$.
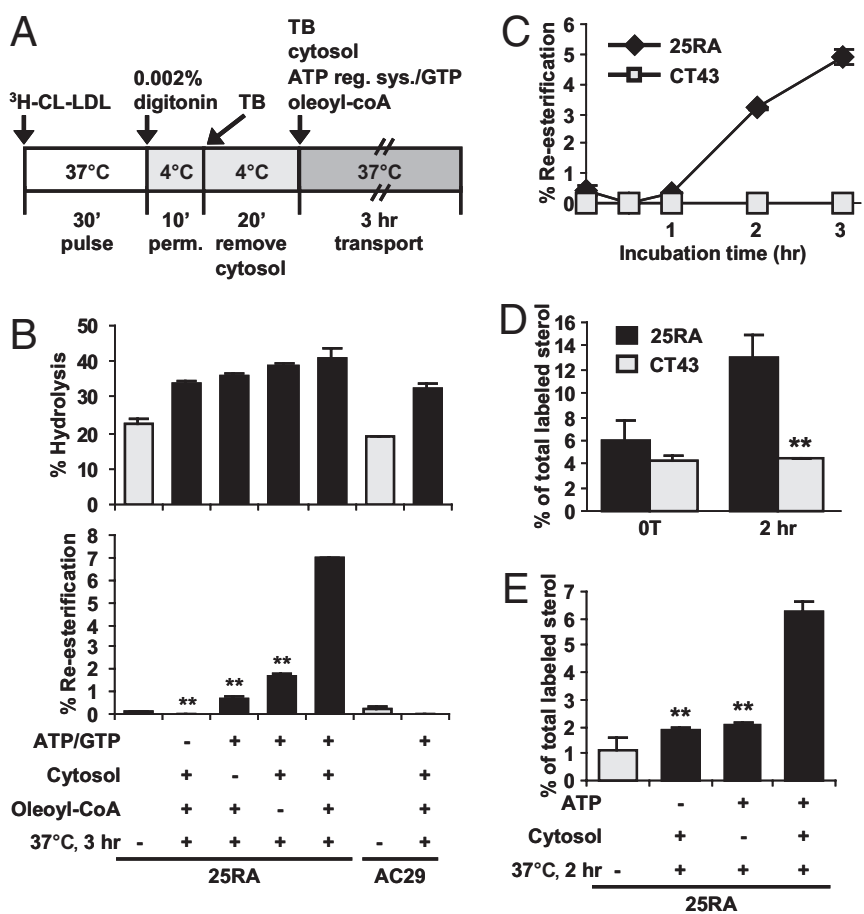

Fig. 3. Cholesterol transport assay in semi-intact cells. (A) Procedure used to conduct the LDL-CHOL transport assay in vitro. (B) Hydrolysis and reesterification in the presence or absence of ATP/GTP, or rat liver cytosol, or oleoyl-CoA as indicated, for $3 \mathrm{~h}$ at $37{ }^{\circ} \mathrm{C}$. (C) Re-esterification in semi-intact 25RA or CT43 cells during the 3 -h incubation time. ( $D$ and $E$ ) ${ }^{3} \mathrm{H}-\mathrm{LDL}-\mathrm{CHOL}$ associated with syntaxin 6-rich membranes in semi-intact 25RA or CT43 cells with or without incubation for $2 \mathrm{~h}(D)$ or in semi-intact 25RA cells with or without ATP or rat liver cytosol during incubation as indicated $(E)$. Values are presented as the percentage of total labeled sterol. Data are means \pm SD from 2 experiments. **, $P<0.01$ by Student's $t$ test.

By contrast, in reconstituted CT43 cell system, re-esterification activity remained undetectable. This demonstrates that the reesterification of ${ }^{3} \mathrm{H}-\mathrm{LDL}-\mathrm{CHOL}$ in the reconstituted system depends on functional NPC1. In reconstituted 25RA cell system, 3\% re-esterification occurred in $2 \mathrm{~h}$ and $5 \%$ in $3 \mathrm{~h}$ (Fig. $3 C$ ); in intact $25 \mathrm{RA}$ cells, $12 \%$ re-esterification occurred in $2 \mathrm{~h}$, and $20 \%$ in $3 \mathrm{~h}$ (Fig. S1B). Thus, the efficiency of the reconstituted system is $\approx 20-25 \%$ of that observed in intact cells. Vesicular trafficking requires soluble ATPases present in the cell cytosol. NEM inhibits ATPases and disrupts vesicular trafficking events in vitro. We tested the possible involvement of soluble ATPases in our in vitro system. The results show that NEM abolished the activity of the cytosol, whereas simultaneous inclusion of DTT partially prevented the inhibitory action of NEM (data not shown).

The results described in Fig. $3 B$ and $C$ suggest that the movement of LDL-CHOL from the NPC1 compartment to the ER in vitro involves vesicular transport. Numerous protein cargos undergo retrograde transport from the EE/recycling endosomes to the TGN by vesicular trafficking (32). To test this hypothesis that the transport of LDL-CHOL from the NPC1 compartment to the TGN may involve a similar mechanism, we performed an LDL-CHOL transport assay in reconstituted 25RA and CT43 cell systems for $2 \mathrm{~h}$, then used the labeled PNSs to perform IA experiments, using antisyntaxin 6 or nonspecific antibodies as the immunoprobes. The results (Fig. 3D) show that a significant increase in association between ${ }^{3} \mathrm{H}$-LDL-CHOL and the syntaxin 6-rich membranes occurred in the reconstituted 25RA cells but not in the reconstituted CT43 cells. An additional experiment (Fig. $3 E$ ) showed that in reconstituted 25RA cells, for ${ }^{3} \mathrm{H}-\mathrm{LDL}-\mathrm{CHOL}$ to be associated with the TGN-rich membranes, both ATP and cytosolic factors are 

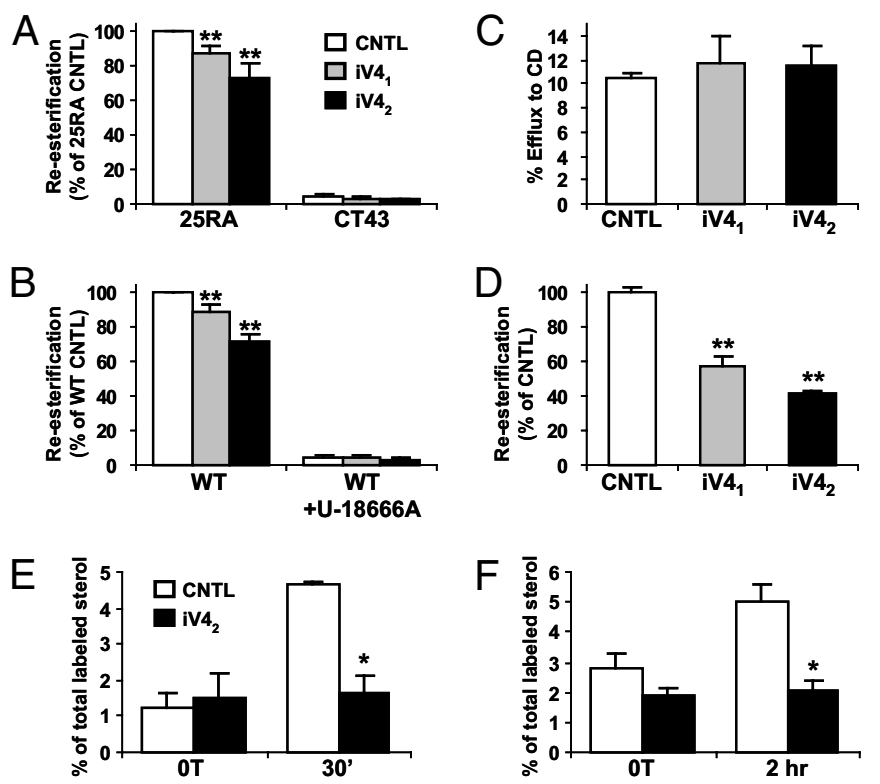

Fig. 4. VAMP4 KDs reduce ${ }^{3} \mathrm{H}-\mathrm{LDL}-\mathrm{CHOL}$ transport in intact $25 \mathrm{RA}$, WT cells, or reconstituted 25RA cell system. The 25RA, CT43, or WT cells were transfected with control (CNTL) or VAMP4 (iV4 $\left.4_{1}, i V 4_{2}\right)$ siRNA and incubated for $48 \mathrm{~h}$ then pulsed with ${ }^{3} \mathrm{H}-\mathrm{CL}-\mathrm{LDL}$. (A) Re-esterification in 25RA or CT43 cells; chase time, $3 \mathrm{~h}$. Data are means \pm SD from 3 experiments. $(B)$ re-esterification in WT cells treated with or without $0.3 \mu \mathrm{M} \mathrm{U}-18666 \mathrm{~A}$; chase time: $6 \mathrm{~h}$. Data are means \pm SD from 3 experiments. (C) Efflux to CD in 25RA cells; chase time, $3 \mathrm{~h}$. Data are means \pm SD from 2 experiments. $(D)$ Re-esterification in reconstituted 25RA cell system. Incubation time, $3 \mathrm{~h}$. Data are means \pm SD from 3 experiments. ( $E$ and $F)^{3} \mathrm{H}$-LDL-CHOL associated with syntaxin 6 -rich membranes in intact 25RA cells at 0T or after 30-min chase $(E)$, in reconstituted 25RA cell system at $0 \mathrm{~T}$, or after 2 -h incubation $(F)$. Data are means \pm SD from 2 experiments. *, $P<0.05 ; * *, P<0.01$ by Student's $t$ test.

required, suggesting that transport of LDL-CHOL from the NPC1 compartment to the TGN involves a vesicular mechanism.

Knocking Down VAMP4/Syntaxin 6/Syntaxin 16 Diminishes the ReEsterification of ${ }^{3} \mathrm{H}$-LDL-CHOL in CHO Cells. The SNARE complex VAMP4/syntaxin 6/syntaxin 16/Vti1a at the TGN plays an important role in mediating the transport of various proteins between the EE/recycling endosomes and the TGN (29). The same SNARE complex may also participate in the transport of LDL-CHOL to the TGN. We took the siRNA knockdown (KD) approach to investigate this possibility. We cloned the Chinese hamster VAMP4, syntaxin 6 and syntaxin 16 cDNAs by PCR amplification (Fig. S4). To guard against possible off-target effect(s) caused by individual siRNAs, we used 2 or 3 siRNAs against different regions for each of these genes ( 2 for VAMP4, 2 for syntaxin 6 , and 3 for syntaxin 16) and monitored the effects of each of these siRNAs on the target protein expression level and on ${ }^{3} \mathrm{H}$-LDL-CHOL transport. We first transfected the 25RA or CT43 cells with siRNA targeted against VAMP4 (iV4 1 or iV4 $4_{2}$ ), or with a control siRNA (CNTL). Immunoblot analyses show that $48 \mathrm{~h}$ after transfection, the $\mathrm{iV} 4 \mathrm{~s}$ reduced VAMP4 protein expression by $\approx 90 \%\left(\mathrm{iV}_{1}\right)$ or $95 \%\left(\mathrm{iV}_{2}\right)$ (Fig. $\mathrm{S} 5 A$ ). The KD of VAMP4 by iV4 did not significantly affect the protein expressions of syntaxin 6, syntaxin 16, EEA1, cav1, NPC1, $\beta$-actin, or ACAT1 (Fig. S5A). We then performed the LDL$\mathrm{CHOL}$ trafficking assays in intact cells after VAMP4 KD. The results show that the re-esterification of ${ }^{3} \mathrm{H}-\mathrm{LDL}-\mathrm{CHOL}$ in $\mathrm{iV} 4$ treated 25RA cells was reduced by $13 \%$ or $27 \%$ (Fig. $4 A$ Left). The re-esterifications in CT43 cells with or without iV4 treatment were, as expected, much lower (Fig. 4A Right). The hydrolysis was slightly diminished by VAMP4 KD in 25RA cells but not in CT43 cells (data not shown). Additional results show that VAMP4 KD did not affect the transport of ${ }^{3} \mathrm{H}-\mathrm{LDL}-\mathrm{CHOL}$ to the PM in 25RA cells (Fig. 4C), suggesting that VAMP4 is involved in transporting LDL-CHOL to the ER but not in transporting it to the PM. We next performed the VAMP4 KD experiments in WT CHO cells. The results show that $\mathrm{iV4} 4_{1}$ or $\mathrm{iV} 4_{2}$ also efficiently reduced the VAMP4 protein expression in treated WT cells, without affecting the expression of other proteins examined (Fig. S5A). The reesterification of ${ }^{3} \mathrm{H}-\mathrm{LDL}-\mathrm{CHOL}$ in $\mathrm{iV} 4_{1}$ or $\mathrm{iV} 4_{2}$ treated WT cells was reduced by $11 \%$ or $28 \%$ (Fig. 4 B Left). In WT cells treated with $\mathrm{U}-18666 \mathrm{~A}$, the re-esterification of ${ }^{3} \mathrm{H}-\mathrm{LDL}-\mathrm{CHOL}$ remained very low with or without iV4 treatment (Fig. 4B Right). We next asked whether the role of VAMP4 in LDL-CHOL transport could be demonstrated in our in vitro system. We performed VAMP4 KDs in 25RA cells, and then conducted the in vitro assay for transport of LDL-CHOL to the ER. The results show that VAMP4 KD (with $\mathrm{iV}_{1}$ or $\mathrm{iV}_{2}$; Fig. $4 D$ ) reduced the re-esterification of ${ }^{3} \mathrm{H}-\mathrm{LDL}$ CHOL by $42 \%$ or $58 \%$. To test whether VAMP4 is involved in the trafficking of LDL-CHOL to the TGN, we treated 25RA cells with an iV4 or with a CNTL siRNA for $48 \mathrm{~h}$, performed the pulse, then chased for $30 \mathrm{~min}$ in intact cells (Fig. $4 E$ ) or chased in the reconstituted cell system for $2 \mathrm{~h}$ (Fig. $4 F$ ), then used the PNSs to perform IA experiments. The results show that a significant increase in association of ${ }^{3} \mathrm{H}-\mathrm{LDL}-\mathrm{CHOL}$ to the syntaxin-6 rich membranes occurred in CNTL treated intact cells or reconstituted cell system, but not in iV4 treated intact cells or reconstituted cell system (Fig. $4 E$ and $F$ ). These results suggest that VAMP4 is involved in transporting LDL-CHOL to the TGN.

We next performed similar siRNA experiments on syntaxin 6. In the 25RA, CT43, and WT cells, after 72-h incubation, the 2 syntaxin 6 siRNAs (iS6 $6_{1}$ and iS $_{2}$ ) reduced the syntaxin 6 expression by $\approx 95 \%$ without significantly affecting the expression of several proteins examined (Fig. S5B). The results of the LDL-CHOL trafficking assay in intact cells showed that iS $6_{1}$ or iS $6_{2}$ reduced the re-esterification of ${ }^{3} \mathrm{H}-\mathrm{LDL}-\mathrm{CHOL}$ by $31 \%$ or $17 \%$ in $25 \mathrm{RA}$ cells (Fig. S6 $A$ Left) and by $57 \%$ or $29 \%$ in WT cells, respectively (Fig. S6B Left). KD of syntaxin 6 did not affect the transport of ${ }^{3} \mathrm{H}-\mathrm{LDL}-\mathrm{CHOL}$ to the PM in 25RA cells (Fig. S6C). In the reconstituted 25RA cell system, syntaxin $6 \mathrm{KD}$ (with iS $6_{1}$ or iS $6_{2}$ ) reduced the re-esterification of ${ }^{3} \mathrm{H}-\mathrm{LDL}-\mathrm{CHOL}$ by $48 \%$ or $32 \%$ (Fig. S6D).

We next performed siRNA KD of syntaxin 16. In 25RA, CT43, or WT cells, after 72-h incubation, the 3 different syntaxin 16 siRNAs reduced syntaxin 16 expression by $50 \%$ (iS16 1 ), $80 \%$ (iS16 2 ), or $70 \%$ (iS16 3 ) of the control value (Fig. S5C). Syntaxin 6 expression was also modestly reduced by the syntaxin $16 \mathrm{KD}$, in agreement with a previous report (33). In 25RA cells, the reesterification of ${ }^{3} \mathrm{H}-\mathrm{LDL}-\mathrm{CHOL}$ was reduced by $42 \%$ (iS16 1 ), $73 \%$ (iS16 $)$, or $58 \%$ (iS16 3 ) (Fig. $5 A$ Left). In WT cells, the reesterification of ${ }^{3} \mathrm{H}-\mathrm{LDL}-\mathrm{CHOL}$ was reduced by $48 \%$ (iS16 1 ), $56 \%$ (iS16 2 ), or 58\% (iS16 $)$ (Fig. 5B Left). Syntaxin 16 KD in 25RA cells also did not significantly affect the transport of ${ }^{3} \mathrm{H}-\mathrm{LDL}-\mathrm{CHOL}$ to the PM (Fig. $5 C$ ). In the reconstituted 25RA cell system, syntaxin $16 \mathrm{KD}$ (with $\mathrm{iS}_{16}$ or $\mathrm{iS}_{2} 6_{3}$ ) reduced the re-esterification of ${ }^{3} \mathrm{H}-\mathrm{LDL}-\mathrm{CHOL}$ by $50 \%$ or $45 \%$ (Fig. $5 \mathrm{D}$ ). Together, these results implicate VAMP4/syntaxin 6/syntaxin 16 in the LDL-CHOL transport pathway in both the 25RA and WT CHO cell lines.

\section{Discussion}

Previously, using filipin as a probe for cholesterol, BlanchetteMackie and colleagues (34) performed cytochemical freezefracture electron microscopy and showed that cholesterol content increased in the Golgi when human fibroblasts were incubated with LDL for $24 \mathrm{~h}$, suggesting the involvement of the Golgi in LDLCHOL transport. However, because of the low sensitivity of the filipin-staining method, the LDL incubation time was necessarily prolonged; this and other technical difficulties prevented the investigators from determining the role of the Golgi in LDL-CHOL transport (discussed in refs. 35-38). In our current work, we 

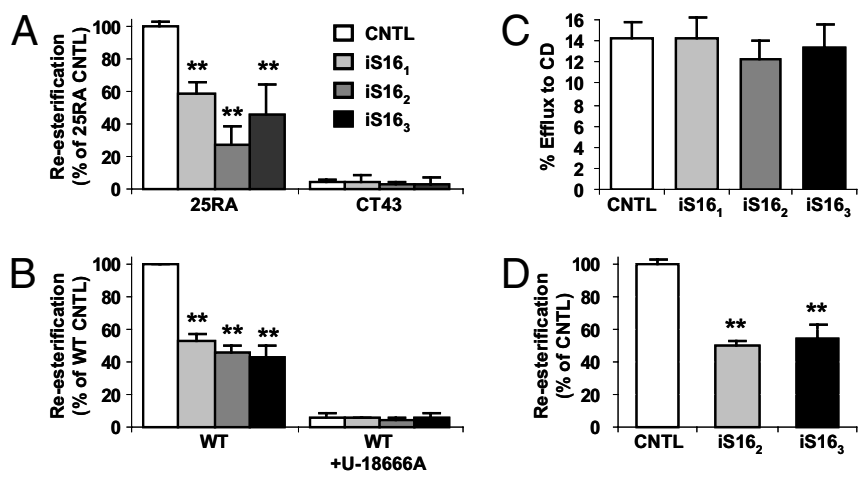

Fig. 5. Syntaxin $16 \mathrm{KD}$ s reduce ${ }^{3} \mathrm{H}$-LDL-CHOL re-esterification in intact $25 \mathrm{RA}$ WT cells, or reconstituted 25RA cell system. The 25RA, CT43, or WT cells were transfected with control (CNTL) or syntaxin 16 (iS16 ${ }_{1}$-iS16 IS $_{3}$ ) siRNA and incubated for $72 \mathrm{~h}$, then pulsed with ${ }^{3} \mathrm{H}-\mathrm{CL}-\mathrm{LDL}$. $(A)$ Re-esterification in the 25RA or CT43 cells; chase time, $3 \mathrm{~h}$. Data are means \pm SD from 3 experiments. $(B)$ Re-esterification in the WT cells treated with or without $0.3 \mu \mathrm{M} \mathrm{U}-18666 \mathrm{~A}$; chase time, $6 \mathrm{~h}$. Data are means \pm SD from 2 experiments. (C) Efflux to CD in the 25RA cells; chase time, $3 \mathrm{~h}$. Data are means \pm SD from 3 experiments. $(D)$ Re-esterification in reconstituted 25RA cell system. Incubation time, $3 \mathrm{~h}$. Data are means \pm SD from 2 experiments. **, $P<0.01$ by Student's $t$ test.

monitored the early itinerary of ${ }^{3} \mathrm{H}$-labeled LDL-CHOL in parental (25RA) and mutant NPC1 (CT43) cells by various biochemical means, and developed an in vitro system to monitor the transport of LDL-CHOL from the NPC1 compartment to the ER. We also performed siRNA KD experiments and showed that VAMP4, syntaxin 6, and syntaxin 16 participate in LDL-CHOL transport to the ER, and that VAMP4 is involved in moving LDL-CHOL from the NPC1 compartment to the TGN (Fig. $4 E$ and $F$ ). We conclude that the transport of a significant portion of LDL-CHOL from the NPC1 compartment to the ER involves vesicular trafficking and the SNARE complex to the TGN.

Our results suggest that VAMP4/syntaxin 6/syntaxin 16 are not directly involved in translocating LDL-CHOL to the PM for sterol efflux. Syntaxin 6 is involved in the rapid delivery of sphingolipids and cellular cholesterol from the TGN to cholesterol rich regions in the PM (i.e., caveolae) (30). In a mammalian cell, within 2-3 h, the initial cellular fates of CHOL newly derived from LDL and that derived from recently synthesized sterols are distinct $(28,39)$; at steady state, cellular cholesterol can rapidly circulate (within minutes) among certain compartments (40-42). Syntaxin 6 may be involved in moving the circulating CHOL (but not newly derived LDL-CHOL) to the PM.

Our results show that neither VAMP4, syntaxin 6, nor syntaxin $16 \mathrm{KD}$ could reduce LDL-CHOL transport by $>70 \%$ (Figs. 4 and 5 and S6), suggesting that more than 1 SNARE complex may be involved in the vesicular transport of LDL-CHOL from the endosomes to the TGN, similarly to what has been demonstrated in protein transport studies $(33,43)$. Assuming nocodazole acts by rapidly disintegrating the TGN, the results presented in Fig. S1D suggest that the endosome to TGN pathway may be responsible for $50 \%$ of the total LDL-CHOL transport to the ER or to the PM in 25RA cells. The results presented in Fig. $5 A$ and $B$ suggest that the TGN-specific SNARE syntaxin 16 may be involved in transporting $60-70 \%$ of the LDL-CHOL from the endosomes to the ER. Both estimates suggest that in $\mathrm{CHO}$ cells, other mechanisms are also involved in transporting LDL-CHOL. In yeast, certain oxysterol binding proteins may be involved in NPC-dependent sterol transport in a nonvesicular manner (44). Further experiments will be required to test the relative importance of vesicular and non-vesicular mechanisms for transporting cholesterol from different sources in different cell types.
We propose a working model to summarize a pathway for LDL-CHOL transport (Fig. S7): the endocytosed CE in LDL undergoes hydrolytic cleavage in a specialized EE; the CHOL liberated enters the NPC1-containing endosomes. By mechanism(s) yet to be revealed, cholesterol-rich vesicles form; these vesicles move to the TGN by vesicular trafficking that involves the SNARE proteins VAMP4, syntaxin 6, and syntaxin 16. From the TGN, the LDL-CHOL moves to the ER for re-esterification by ACAT1, or moves to the PM. Additional trafficking mechanism(s) also exist to transport LDL-CHOL. For example, in mutant NPC cells, overexpressing Rab9, a small GTPase enriched in the LE/LYS, efficiently rescues the LE/LYS cholesterol accumulation phenotype $(45,46)$. The following scenario may occur: In NPC1-null cells, LDL-CHOL enters the endosomes but cannot exit normally. It rapidly moves to the LE/LYS where it accumulates. A Rab9-dependent NPC1-independent cholesterol translocation pathway occurs between the LE/LYS and the TGN but operates at low efficiency. Overexpressing the Rab9 protein increases the efficiency of this pathway and bypasses the need for NPC1. It will be important to further dissect the molecular machineries involved in transporting LDL-CHOL. The availability of the reconstituted cell system described in this work should facilitate these studies.

\section{Materials and Methods}

LDL-Derived Cholesterol Trafficking Assays. The 25RA and CT43 cells were cultured in 6-well dishes in Medium A for 2-3 days, pulsed with $30 \mu \mathrm{g} / \mathrm{ml}{ }^{3} \mathrm{H}-\mathrm{CL}-\mathrm{LDL}$ in Medium A for $30 \mathrm{~min}$ at $37^{\circ} \mathrm{C}$, and chased in Medium A for 0-6 h (Fig. S1 $A$ ). The labeled lipids were extracted and analyzed on silver nitrate impregnated TLC plates (47); the percentage hydrolysis of ${ }^{3} \mathrm{H}-\mathrm{CL}$ and the percentage re-esterification of ${ }^{3} \mathrm{H}-\mathrm{LDL}-\mathrm{CHOL}$ were calculated as described (2). To conduct the cholesterol efflux experiments, cells were incubated with 4\% 2-hydroxypropyl- $\beta$-CD in Medium $\mathrm{D}$ at $37^{\circ} \mathrm{C}$ during the last $10 \mathrm{~min}$ of the chase period (2). Previously, we employed a "release of a temperature block" method to monitor the fate of ${ }^{3} \mathrm{H}-\mathrm{LDL}-\mathrm{CHOL}$ (2). Control experiments show that the pulse-chase protocol described here reproduces all of the findings described in ref. 2 . The WT cells were cultured in Medium A for 2 days, switched to Medium D with or without $0.3 \mu \mathrm{M}$ U-18666A for $24 \mathrm{~h}$, and chased in Medium A with or without U-18666A.

Immunoadsorption. Four hundred microliters of PNS material mixing with $200 \mu \mathrm{l}$ of $60 \%$ OptiPrep solution, cleared by centrifuging at $15,000 \times g$ for $10 \mathrm{~min}$, was used as the starting material. Alternatively, PNS was subject to 5-25\% OptiPrep gradient ultracentrifugation for $3 \mathrm{~h}$; fraction 5 was used as the starting material. $150 \mu \mathrm{L}$ of the starting material were incubated for $1.5 \mathrm{~h}$ on ice with $150 \mathrm{mM} \mathrm{NaCl}$ and $2 \mu \mathrm{L}$ of anti-syntaxin 16 antiserum or $2 \mu \mathrm{g}$ of anti-syntaxin $6 \mathrm{IgG}$, or the same amount of nonspecific rabbit antiserum or IgGs in final vol. of $200 \mu \mathrm{L}$; the mixtures were incubated for $30 \mathrm{~min}$ on ice with $40 \mu \mathrm{L}$ of $\mu \mathrm{Macs}$ Protein A MicroBeads (Miltenyi Biotec), loaded onto the $\mu \mathrm{Col}-$ umn, the flowthrough (FT) was collected. After washing the beads with $800 \mu \mathrm{L}$ of $\mathrm{HB}$ containing $150 \mathrm{mM} \mathrm{NaCl}$, the proteins bound to the beads were eluted with $100 \mu \mathrm{L}$ of $1 \times$ SDS/PAGE sample buffer. Equal aliquots of the total input, eluate and FT samples were analyzed by immunoblots by using appropriate antibodies. The ${ }^{3} \mathrm{H}$-labeled lipids bound to beads were collected by eluting beads with $500 \mu \mathrm{L}$ of chloroform/methanol (2:1) and analyzed by TLC (2).

LDL-CHOL Transport Assay in Digitonin-Permeabilized Semi-Intact Cells. The assay was based on the assay developed to monitor protein transport between organelles in vitro (29). Cells were grown in Medium A in 6-well dishes, labeled with $30 \mu \mathrm{g} / \mathrm{ml}$ ${ }^{3} \mathrm{H}-\mathrm{CL}-\mathrm{LDL}$ in Medium A for $30 \mathrm{~min}$ at $37^{\circ} \mathrm{C}$, then placed on ice, 
washed twice with ice-cold transport buffer (TB, $25 \mathrm{mM}$ Hepes$\mathrm{KOH}, \mathrm{pH} 7.2,115 \mathrm{mM}$ potassium acetate, $2.5 \mathrm{mM} \mathrm{MgCl}_{2}$ ), and incubated for $10 \mathrm{~min}$ with $20 \mu \mathrm{g} / \mathrm{ml}(0.002 \%)$ digitonin in $\mathrm{TB}$ at $4{ }^{\circ} \mathrm{C}$. The permeabilized cells were washed with ice-cold TB and incubated in TB for $20 \mathrm{~min}$ at $4{ }^{\circ} \mathrm{C}$ to remove the residual cytosol. Over $99 \%$ of cells become permeabilized, as assessed by trypan blue staining. The semi-intact cells were incubated at $37^{\circ} \mathrm{C}$ in $500 \mu \mathrm{L}$ of TB with the following reagents: $200 \mu \mathrm{g}$ of rat liver cytosol (Xenotech), the ATP regeneration system (1 mM ATP, $10 \mathrm{mM}$ creatine phosphate (Alfa Aesar), 10 units/ml creatine phosphokinase, $0.1 \mathrm{mg} / \mathrm{ml}$ BSA, $10 \mathrm{mM}$ Hepes-KOH, pH 7.2), $250 \mu \mathrm{M}$ GTP, $50 \mu \mathrm{M}$ oleoyl-CoA, and $0.8 \mathrm{mM}$ magnesium acetate, for various times. After incubation, the reaction was stopped by adding $500 \mu \mathrm{L}$ of $0.4 \mathrm{M} \mathrm{NaOH}$, and the cells were incubated for $30 \mathrm{~min}$ at room temperature. Labeled lipids were extracted and analyzed by TLC. To monitor the transport of

1. Brown MS, Goldstein JL (1986) A receptor-mediated pathway for cholesterol homeostasis. Science 232:34-47.

2. Sugii S, Reid PC, Ohgami N, Du H, Chang TY (2003) Distinct endosomal compartments in early trafficking of low density lipoprotein-derived cholesterol. J Biol Chem 278:27180-27189.

3. Wojtanik KM, Liscum L (2003) The transport of LDL-derived cholesterol to the plasma membrane is defective in NPC1 cells. J Biol Chem 278:14850-14856.

4. Frolov A, etal. (2003) NPC1 and NPC2 regulate cellular cholesterol homeostasis through generation of low density lipoprotein cholesterol-derived oxysterols. J Biol Chem 278:25517-25525.

5. Chang TY, et al. (2001) Roles of acyl-coenzyme A:cholesterol acyltransferase-1 and -2. Curr Opin Lipidol 12:289-296.

6. Garver WS, Heidenreich RA, Erickson RP, Thomas MA, Wilson JM (2000) Localization of the murine Niemann-Pick C1 protein to two distinct intracellular compartments. J Lipid Res 41:673-687.

7. Karten B, Campenot RB, Vance DE, Vance JE (2006) The Niemann-Pick C1 protein in recycling endosomes of presynaptic nerve terminals. J Lipid Res 47:504-514.

8. Ko DC, Gordon MD, Jin JY, Scott MP (2001) Dynamic movements of organelles containing Niemann-Pick C1 protein: NPC1 involvement in late endocytic events. Mol Biol Cell 12:601-614.

9. Chikh K, Vey S, Simonot C, Vanier MT, Millat G (2004) Niemann-Pick type C disease: Importance of $\mathrm{N}$-glycosylation sites for function and cellular location of the NPC2 protein. Mol Genet Metab 83:220-230.

10. Ohgami N, et al (2004) Binding between the Niemann-Pick C1 protein and a photoactivatable cholesterol analog requires a functional sterol-sensing domain. Proc Natl Acad Sci USA 101:12473-12478.

11. Infante RE, et al. (2008) Purified NPC1 protein. I. Binding of cholesterol and oxysterols to a 1278-amino acid membrane protein. J Biol Chem 283:1052-1063.

12. Infante RE, et al. (2008) Purified NPC1 protein: Il. Localization of sterol binding to a 240-amino acid soluble luminal loop. J Biol Chem 283:1064-1075.

13. Ko DC, Binkley J, Sidow A, Scott MP (2003) The integrity of a cholesterol-binding pocket in Niemann-Pick C2 protein is necessary to control lysosome cholesterol levels. Proc Natl Acad Sci USA 100:2518-2525.

14. Millard EE, et al. (2005) The sterol-sensing domain of the Niemann-Pick C1 (NPC1) protein regulates trafficking of low density lipoprotein cholesterol. I Biol Chem 280:28581-28590

15. Cheruku SR, Xu Z, Dutia R, Lobel P, Storch J (2006) Mechanism of cholesterol transfer from the Niemann-Pick type C2 protein to model membranes supports a role in lysosomal cholesterol transport. J Biol Chem 281:31594-31604.

16. Sleat DE, et al. (2004) Genetic evidence for nonredundant functional cooperativity between NPC1 and NPC2 in lipid transport. Proc Natl Acad Sci USA 101:5886-5891.

17. Chang TY, Limanek JS (1980) Regulation of cytosolic acetoacetyl coenzyme A thiolase, 3-hydroxy-3-methylglutaryl coenzyme A synthase, 3-hydroxy-3-methylglutaryl coenzyme A reductase, and mevalonate kinase by low density lipoprotein and by 25 hydroxycholesteral in Chinese hamster ovary cells. J Biol Chem 255:7787-7795.

18. Hua X, Sakai J, Brown MS, Goldstein JL (1996) Regulated cleavage of sterol regulatory element binding proteins requires sequences on both sides of the endoplasmic retic ulum membrane. J Biol Chem 271:10379-10384.

19. Cruz JC, Sugii S, Yu C, Chang TY (2000) Role of Niemann-Pick type C1 protein in intracellular trafficking of low density lipoprotein-derived cholesterol. J Biol Chem 275:4013-4021.

20. Yamauchi $Y$, et al. (2007) Plasma membrane rafts complete cholesterol synthesis by participating in retrograde movement of precursor sterols. J Biol Chem 282:3499435004

21. Pipalia NH, Hao M, Mukherjee S, Maxfield FR (2007) Sterol, protein and lipid trafficking in Chinese hamster ovary cells with Niemann-Pick type C1 defect. Traffic 8:130-141.

22. Reid PC, Sugii S, Chang TY (2003) Trafficking defects in endogenously synthesized cholesterol in fibroblasts, macrophages, hepatocytes, and glial cells from NiemannPick type C1 mice. J Lipid Res 44:1010-1019.

23. Liscum $L$ (1990) Pharmacological inhibition of the intracellular transport of low-density lipoprotein-derived cholesterol in Chinese hamster ovary cells. Biochim Biophys Acta 1045:40-48.
LDL-CHOL to syntaxin 6-rich region in vitro, the semi-intact cells with or without incubation for $2 \mathrm{~h}$ in transport reaction mix, as indicated, were scraped and homogenized by using a glass homogenizer (with 20 strokes), followed by centrifugation at $16,000 \times \mathrm{g}$ for $10 \mathrm{~min}$ in $20 \%$ OptiPrep. The resultant PNSs were incubated with appropriate antibodies as indicated, then incubated with $\mu$ Macs Protein A MicroBeads, and processed in the same manner as the immunoadsorption procedure described above.

Additional materials and methods are described in SI Materials and Methods.

ACKNOWLEDGMENTS. We thank Drs. Charles Barlowe, William Wickner, Gustav E. Lienhard, and Naomi Sakashita for stimulating discussions and Dr. Richard H. Scheller (Genentech, Inc., South San Francisco, CA) for anti-syntaxin 6 antibodies. This work is supported by National Institutes of Health Grant HL 36709 (to T.Y.C.).

24. Yang W, Storrie B (1998) Scattered Golgi elements during microtubule disruption are initially enriched in trans-Golgi proteins. Mol Biol Cell 9:191-207.

25. Sciaky NJ, et al. (1997) Golgi tubule traffic and the effects of brefeldin A visualized in living cells. J Cell Biol 139:1137-1155.

26. Neufeld EB, et al. (1996) Intracellular trafficking of cholesterol monitored with a cyclodextrin. J Biol Chem 271:21604-21613.

27. Kobayashi T, et al. (1999) Late endosomal membranes rich in lysobisphosphatidic acid regulate cholesterol transport. Nat Cell Biol 1:113-118.

28. Liscum L, Ruggiero RM, Faust JR (1989) The intracellular transport of low density lipoprotein-derived cholesterol is defective in Niemann-Pick type C fibroblasts. J Cell Biol 108:1625-1636.

29. Mallard F, et al. (2002) Early/recycling endosomes-to-TGN transport involves two SNARE complexes and a Rab6 isoform. J Cell Biol 156:653-664.

30. Choudhury A, Marks DL, Proctor KM, Gould GW, Pagano RE (2006) Regulation of caveolar endocytosis by syntaxin 6-dependent delivery of membrane components to the cell surface. Nat Cell Biol 8:317-328.

31. Chang CC, Huh HY, Cadigan KM, Chang TY (1993) Molecular cloning and functional expression of human acyl-coenzyme A:cholesterol acyltransferase cDNA in mutant Chinese hamster ovary cells. J Biol Chem 268:20747-20755.

32. Bonifacino JS, Rojas R (2006) Retrograde transport from endosomes to the trans-Golgi network. Nat Rev Mol Cell Biol 7:568-579.

33. Coxey RA, Pentchev PG, Campbell G, Blanchette-Mackie EJ (1993) Differential accumulation of cholesterol in Golgi compartments of normal and Niemann-Pick type $C$ fibroblasts incubated with LDL: A cytochemical freeze-fracture study. J Lipid Res 34:1165-1176

34. Liscum L (1998) in Intracellular Cholesterol Trafficking, eds Chang TY, Freeman DA (Kluwer, Boston), pp 75-92.

35. Ikonen E (2008) Cellular cholesterol trafficking and compartmentalization. Nat Rev Mol Cell Biol 9:125-138.

36. Maxfield FR, Tabas I (2005) Role of cholesterol and lipid organization in disease. Nature 438:612-621.

37. Chang TY, Chang CC, Ohgami N, Yamauchi Y (2006) Cholesterol Sensing, Trafficking and Esterification. Annu Rev Cell Dev Biol 22:129-157.

38. Cruz JC, Chang TY (2000) Fate of Endogenously Synthesized Cholesterol in NiemannPick Type C1 Cells. J Biol Chem 275:41309-41316.

39. Lange Y, Ye J, Steck TL (1998) Circulation of cholesterol between lysosomes and the plasma membrane. J Biol Chem 273:18915-18922.

40. Mukherjee SX, Zha X, Tabas I, Maxfield FR (1998) Cholesterol distribution in living cells: Fluorescence imaging using dehydroergosterol as a fluorescent cholesterol analog. Biophys J 75:1915-1925.

41. Fielding PE, Fielding CJ (1996) Intracellular transport of low density lipoprotein derived free cholesterol begins at clathrin-coated pits and terminates at cell surface caveolae. Biochemistry 35:14932-14938.

42. Tai G, et al. (2004) Participation of the syntaxin 5/Ykt6/GS28/GS15 SNARE complex in transport from the early/recycling endosome to the trans-Golgi network. Mol Biol Cell 15:4011-4022.

43. Ganley IG, Espinosa E, Pfeffer SR (2008) A syntaxin 10-SNARE complex distinguishes two distinct transport routes from endosomes to the trans-Golgi in human cells. J Cell Biol 180:159-172.

44. Yang $\mathrm{H}$ (2006) Nonvesicular sterol transport: Two protein families and a sterol sensor? Trends Cell Biol 16:427-432.

45. Choudhury A, et al. (2002) Rab proteins mediate Golgi transport of caveola internalized glycosphingolipids and correct lipid trafficking in Niemann-Pick C cells. J Clin Invest 109:1541-1550.

46. Walter M, Davies JP, loannou YA (2003) Telomerase immortalization upregulates Rab9 expression and restores LDL cholesterol egress from Niemann-Pick C1 late endosomes. $J$ Lipid Res 44:243-253.

47. Cadigan KM, Spillane DM, Chang TY (1990) Isolation and characterization of Chinese hamster ovary cell mutants defective in intracellular low density lipoproteincholesterol trafficking. J Cell Biol 110:295-308. 